\title{
LA ECONOMÍA SOCIAL Y SOLIDARIA EN EL CONSTITUCIONALISMO ANDINO:
}

LOS CASOS DE ECUADOR Y DE BOLIVIA: SENTIDO HISTÓRICO E IDENTIDAD CULTURAL.

\author{
THE SOCIAL AND SOLIDARITY ECONOMY IN THE ANDEAN \\ CONSTITUTIONALISM: \\ THE CASES OF ECUADOR AND BOLIVIA: HISTORICAL SIGNIFICANCE \\ AND CULTURAL IDENTITY.
}

RESUMEN: Este artículo indaga en el sentido y alcance de la inserción constitucional que presenta la economía social y solidaria, en sus actuales dimensiones, en Bolivia y Ecuador en su condición de Estados andinos que decidieron contemplar las recientes expresiones de la economía social en sus respectivas cartas políticas. El trabajo permite apreciar que la regulación de la economía social y solidaria en los Constituciones de Bolivia y Ecuador, a pesar de las diferencias entre ambos textos, reconoce la conexión de esta alternativa económica con una concepción tradicional sobre el desarrollo, en la cual convergen principios y valores referentes a la identidad cultural y a la historia de las sociedades de ambos países. Con un carácter predominantemente descriptivo y mediante un enfoque cualitativo se examina los dispositivos constitucionales pertinentes en la materia y se analizan determinadas interpretaciones doctrinarias sobre los fundamentos y las orientaciones que subyacen a la noción de economía social y solidaria contenida en las constituciones de ambos países.

PALABRAS CLAVES: Constitucionalismo Andino - Economía Social y Solidaria - Bolivia -Ecuador

ABSTRACT: This article deals with the meaning and scope of the constitutional insertion of the social and solidarity economy, in its current dimensions, in Bolivia and Ecuador, like expression of Andean countries that decided to regulate the modern manifestation of the social economy in their Federal Constitutions. The paper indicates that the regulation of the social and solidarity economy in the Constitutions of Bolivia and Ecuador, despite the differences between both laws, recognises the connection of this economic alternative with a development traditional conception that includes principles and values concerning to the cultural identity and the history of the societies of both countries. With a predominantly descriptive character and through a qualitative approach, the constitutional rules in the issue are examined and some interpretations of the authors about the basis and orientations of the social economy notion contained in the constitutions of both countries are analysed.

KEYWORDS: Andean Constitutionalism - Social and Solidarity Economy - Bolivia -Ecuador

\footnotetext{
${ }^{1}$ Doctor en Humanidades por la Universidad Nacional de Tucumán [Argentina]; Doctor en Derecho por la Universidad de Buenos Aires [Argentina]; Investigador del Consejo Nacional de Investigaciones Científicas y Técnicas de Argentina [CONICET]. Profesor de la Universidad Católica de Santiago del Estero [UCSE; Argentina]
} 


\section{INTRODUCCIÓN}

Desde las últimas décadas de la centuria pasada y, de modo más intenso, a comienzos del presente siglo, la economía social y solidaria recogió diferentes manifestaciones en las sociedades sudamericanas. Muchas de estas iniciativas, en buena medida, resultaron explicadas por las secuelas socialmente excluyentes de las políticas neoliberales que, en diferente magnitud, se implementaron en la región y frente a las cuales procuraron erigirse en instrumentos de reinserción social y laboral. Estas alternativas terminaron renovando la fisonomía que, tradicionalmente, caracterizó a la economía social, al diversificar su contenido con la incorporación de nuevas expresiones que guardan cierta distancia conceptual con las figuras clásicas de esta variante de la economía.

La relevancia que fueron asumiendo estas recientes modalidades, entendible en parte por la cobertura oficial de las mismas a través de políticas públicas dirigidas a estimularlas y, también, en parte por la propia difusión y recepción social de estos emprendimientos, determinó que los ordenamientos jurídicos de algunos países del subcontinente abordaran normativamente diferentes aspectos implicados en los nuevos desarrollos que ofrece la economía solidaria. Precisamente, el objetivo de esta contribución radica en indagar en el sentido y alcance de la inserción constitucional que presenta la economía social, en sus actuales dimensiones, en aquellos Estados de Sudamérica que decidieron contemplarlas en sus cartas políticas. Al respecto, corresponde apuntar que el artículo permite apreciar que la regulación de la economía social y solidaria en los Constituciones de Bolivia y Ecuador, a pesar de las diferencias entre ambos textos, reconoce la conexión de esta alternativa económica con una concepción tradicional sobre el desarrollo, en la cual convergen principios y valores referentes a la identidad cultural y a la historia de las sociedades de ambos países.

El trabajo presenta un carácter esencialmente descriptivo $\mathrm{y}$, desde una perspectiva metodológica, se inscribe en el tipo cualitativo. Para el desarrollo del objetivo trazado, se procede a examinar las constituciones de Bolivia y de Ecuador, reformadas ambas en el decenio anterior. La indagación en los aspectos referentes a la inserción de la economía social y solidaria en las cartas políticas de estos dos países adquiere un significado adicional desde la perspectiva del conocimiento específico, debido a las orientaciones que se imprimieron a sendos textos constitucionales a partir de sus revisiones recientes. Por tal razón se consideran, 
también, determinadas posiciones doctrinarias sobre los fundamentos y las orientaciones que subyacen a la noción de economía social y solidaria contenida en las constituciones de ambos países

Justamente, tal circunstancia explica la estructura de este aporte. De este modo, en el primer aparatado se procura caracterizar a algunas de las orientaciones y fundamentos que particularizan a las constituciones de los Estados mencionados y que suponen un rescate de valores y principios fuertemente arraigados en el legado histórico y cultural de sus poblaciones, como así también una consulta a la diversidad que atraviesa la composición de sus respectivas sociedades. A continuación, se profundiza en el sentido y la relevancia asignada a la economía social en los textos constitucionales de los países citados, considerando, en su caso, el modo en que la tipología popular de la economía se articula con las orientaciones y fundamentos referidos. Finalmente, se exponen una serie de reflexiones a modo de cierre.

\section{PLURINACIONALIDAD Y COSMOVISIÓN INDÍGENA EN EL CONSTITUCIONALISMO ANDINO}

Una acabada comprensión de los preceptos constitucionales requiere de una interpretación que no prescinda del encuadre sistemático de los mismos dentro de la totalidad de la carta política. Teniendo en cuenta ello al considerar la inserción de la economía social en las leyes fundamentales de Bolivia y Ecuador no puede soslayarse, en tanto aspectos que caracterizan al constitucionalismo andino de los últimos años, el reconocimiento de la conformación plurinacional del núcleo social de ambos países y la incorporación de conceptos centrales provenientes de la cultura indígena propia de la región. La cobertura constitucional de estas dos cuestiones responde a un trayecto de presencia y resistencia protagonizado por movimientos indígenas que lograron posicionar en la agenda política tópicos vinculados a sus intereses.

Desde la perspectiva de la diversidad, comprendida en un sentido amplio, la mencionada apertura del temario derivó en una revisión del alcance de la democracia al plantear la necesidad de incluir efectivamente a estas comunidades originarias resolviendo las 
diferencias y, por lo tanto, despojar al Estado de su carácter excluyente e imprimirle un contenido plurinacional y multiétnico (Silva Portero, 2008, p. 114).

Este propósito de asegurar la plurinacionalidad se encuentra previsto de modo inicial en las respectivas cartas políticas de Bolivia y Ecuador. Así, en el preámbulo de la Constitución del primer país mencionado se resalta la composición plural del pueblo boliviano, señalándose que se pretende construir un "Estado basado en el respeto e igualdad entre todos...con respeto a la pluralidad económica, social, jurídica, política y cultural de los habitantes". A través del artículo $1^{\circ}$ se reafirma tal orientación al establecer que se “constituye en un Estado Unitario Social de Derecho Plurinacional Comunitario, libre, independiente, soberano, democrático, intercultural" (art.1), fundándose, de este modo, un país "en la pluralidad y el pluralismo político, económico, jurídico, cultural y lingüístico, dentro del proceso integrador del país" (art.1).

A su vez, se refuerza el sentido plurinacional con la incorporación del componente indígena al modelo estadual proyectado, señalándose que la nación se halla integrada por "las naciones y pueblos indígena originario campesinos, y las comunidades interculturales y afrobolivianas" (art. 3). En concordancia con ello se reconoce la "existencia precolonial de las naciones y pueblos indígena originario campesinos y su dominio ancestral sobre sus territorios" (art. 2); razón por la cual se les "garantiza su libre determinación en el marco de la unidad del Estado, que consiste en su derecho a la autonomía, al autogobierno, a su cultura, al reconocimiento de sus instituciones y a la consolidación de sus entidades territoriales" (art. 2).

Del mismo modo, la constitución ecuatoriana de 2008, destina su primer dispositivo para destacar la naturaleza plurinacional del Estado que regla. Así, define al país como "un Estado constitucional de derechos y justicia, social, democrático, soberano, independiente, unitario, intercultural, plurinacional y laico" (art. 1). La inclusión de las comunidades originarias en ese orden plurinacional institucionalizado surge, expresamente, de la caracterización que el texto constitucional efectúa de la nacionalidad ecuatoriana al catalogarla como "el vínculo jurídico político de las personas con el Estado, sin perjuicio de su pertenencia a alguna de las nacionalidades indígenas que coexisten en el Ecuador" (art. 6).

Puede entenderse, siguiendo a Rivera Santibañez (p. 102), que la concepción plurinacional del Estado, que importa la convergencia de varias naciones y pueblos indígenas originarios campesinos, ordenados social, política y jurídicamente a partir de una misma 
constitución y un gobierno estatal, que les garantizan el reconocimiento de su territorio propio, su régimen económico, su sistema jurídico y el derecho a autogobernarse, disponiendo para ello de competencias administrativas, económicas y culturales. De esta manera, la institucionalización de la plurinacionalidad se traduce en un "Estado unitario en el cual los pueblos y nacionalidades pueden ejercer gobierno en un territorio determinado, observando el marco constitucional (Paz y Miño Cepeda y Pazmiño, 2008, p. 41).

Por consiguiente, en tanto que la impresión de un carácter plurinacional al Estado persigue, en lo atinente a la ciudadanía, "el reconocimiento jurídico por parte del Estado a las nacionalidades y pueblos indígenas en tanto entidades colectivas, jurídica-políticas e históricamente constituidas, y como sujetos colectivos de derechos" (Simbaña, 2008, p, 111), puede afirmarse que la consagración constitucional de la plurinacionalidad configura "el reconocimiento más categórico de la condición de diferencia de los pueblos indígenas en el marco del Estado unitario" (Vega Ugalde, 2008, p. 95).

Los avances alcanzados por las comunidades originarias también se canalizaron a través de la inclusión en las letras constitucionales de ciertas nociones ancestrales, inscriptas en la filosofía andina, que proporcionan patrones rectores para la conducción societaria y la administración estatal y que ostentan un sustancial significado para sendas sociedades. De esta manera, y en lo referente a este punto, las conquistas del movimiento indígena se cristalizó en la inserción de los rotulados "principios ético-morales de la sociedad plural”, dentro de los cuales pueden citarse el suma qamaña (vivir bien), el teko kavi (vida buena), o el ñandereko (vida armoniosa). Por su parte, en el supuesto ecuatoriano, esta tendencia se manifestó mediante la recepción del principio del sumak kawsay o buen vivir (Silva Portero, 2008, p. 114).

Precisamente, para Silva Portero (2008, p. 114) la normación constitucional de esta clase de principios podría calificarse:

Como un paso en la conformación de un Estado plural e incluyente que incorpora la perspectiva indígena en su proyecto político y, por lo tanto, como una respuesta al cuestionamiento que los movimientos indígenas han realizado a los principios que tradicionalmente han guiado al ejercicio del poder y a la democracia.

Estos postulados fuertemente anclados en la historia de las poblaciones andinas comportan la asunción de un enfoque amplio e integrador a partir del cual puede concebirse el desenvolvimiento de las sociedades y la relación del individuo con su entorno. En 
consecuencia, puede decirse que la irrupción constitucional de estos principios contribuye a robustecer la consigna, recogida por el constitucionalismo actual, de resguardar y preservar el medio ambiente y la diversidad biológica. En este sentido, apunta Zaffaroni (2010, p.120) que:

Es clarísimo que en ambas constituciones la Tierra asume la condición de persona, en forma expresa en la ecuatoriana y tácita en la boliviana, pero con iguales efectos: cualquiera puede reclamar sus derechos, sin que se requiera que sea afectado personalmente, supuesto que es primario si se la considerase un derecho exclusivo de los humanos.

La ley fundamental boliviana de 2008 no sólo reconoce estas pautas ancestrales enraizadas en la cosmovisión indígena andina, sino que los asimila como criterios finales que deben orientar la labor estatal y el orden social. De este modo, el "buen vivir" es considerado en el preámbulo mismo como un objetivo prevaleciente e inspirador del despliegue estatal y de la organización social. Sin apartarse de aquella óptica que propicia una lectura integradora del hombre y su ambiente se señala, en el referido preámbulo, que se asiste a la construcción de un Estado nuevo fundado:

En el respeto e igualdad entre todos, con principios de soberanía, dignidad, complementariedad, solidaridad, armonía y equidad en la distribución y redistribución del producto social, donde predomine la búsqueda del vivir bien; con respeto a la pluralidad económica, social, jurídica, política y cultural de los habitantes de esta tierra; en convivencia colectiva con acceso al agua, trabajo, educación, salud y vivienda para todos.

La observancia de los postulados derivados de las tradiciones indígenas asoma en la Constitución boliviana como una definición esencial del orden plurinacional instituido, al disponer la adopción y promoción, por parte del Estado, en la calidad de principios éticomorales de la sociedad plural, a los premisas "ama qhilla, ama llulla, ama suwa (no seas flojo, no seas mentiroso ni seas ladrón), suma qamaña (vivir bien), ñandereko (vida armoniosa), teko kavi (vida buena), ivi maraei (tierra sin mal) y qhapaj ñan (camino o vida noble)" (art. 8) .

Por su parte, en la carta política ecuatoriana de 2009 la incorporación de la cosmovisión indígena andina se materializa a través de la constitucionalización del principio del "buen vivir" o sumak kawsay. Este concepto, de origen quechua y de raíces indígenas andino-amazónicas semejante al suma qamaña aymara, significa "buen vivir" o "pleno vivir" 
y contenido hace referencia a la ética que debe orientar tanto el accionar estatal como los vínculos de las personas entre sí y con respecto a la naturaleza (Zaffaroni, 2010, p. 121).

Comenta Vega (2014, p. 170) que en el concepto del "buen vivir" es posible distinguir una serie de elementos relevantes que reposan sobre la idea de armonía. El primero de ellos lo aporta su referencia a la existencia armónica que inspira las relaciones comunitarias en las comunidades indígenas. El segundo componente alude a la convivencia armónica tanto en lo relativo a los individuos entre sí como en lo concerniente a su interacción con la naturaleza, lo cual puede entenderse como la necesidad de la concurrencia de restricciones sociales y ambientales que limiten el comportamiento humano para preservar tal armonía. El tercer es que tal convivencia armónica, que el "buen vivir" pregona, debe construirse dentro de los parámetros de la interculturalidad, razón por la cual su consecución demanda el compromiso activo de los ciudadanos y de los pueblos originarios.

Para una apropiada comprensión de su alcance debe tenerse en cuenta que se trata de un principio filosófico, de significado concreto, originado en el pensamiento indígena (Silva Portero, 2008, p. 123). De conformidad con la filosofía andina, su campo de aplicación lo representa de la realidad en sus diferentes ámbitos y en donde el equilibrio adquiere el sentido de una vida plena (Silva Portero, 2008, p. 123). Ciertamente, de acuerdo a la visión filosófica andina, la existencia en plenitud se logra cuando se alcanza un equilibrio entre la razón, los sentimientos y los instintos que constituyen las fuerzas que componen la realidad el ser (Silva Portero, 2008, p. 119).

Por su propia amplitud y su alcance integrador en el cual el individuo es considerado en interacción recíproca con el ambiente, suministra una perspectiva que no se agota en la clásica imagen del bien común. En tal dirección, enseña Zaffaroni (2010, p. 121).que el principio del sumak kawsay no alude al:

Tradicional bien común reducido o limitado a los humanos, sino del bien de todo lo viviente (si se prefiere, hoy se diría respeto por la biodiversidad), incluyendo por supuesto a los humanos, entre los que exige complementariedad y equilibrio, no siendo alcanzable individualmente.

Resulta conveniente mencionar que la interpretación del buen vivir no ofrece un escenario uniforme tanto entre los autores como en el ámbito de los actores sociales y políticos. Al respecto Vega (2014, p. 170) describe un panorama en el cual identifica tres lecturas concurrentes. Por un lado, la línea indigenista que reniega del sentido con el cual se 
utiliza asocia al "buen vivir", en el entendimiento de que el mismo se aleja de la espiritualidad y de la cosmovisión propia del principio indígena del sumak kawsay. Otro enfoque lo suministra la corriente socialista y estatista que se focaliza en la gestión política-estatal del buen vivir y en los elementos atinentes a la equidad social, que se plasma en la figura del "socialismo del buen vivir" y nutre el "Plan Nacional del Buen Vivir". Por otra parte, para la posición post-desarrollista y ecologista, cristalizada en la Constitución de 2008, el "buen vivir" representa una alternativa cuya construcción requiere de la participación democrática de todos.

Precisamente, para la postura post-desarrollista la incorporación del "buen vivir" representa un modelo de desenvolvimiento societario centrado en la búsqueda de la convivencia armónica, que ofrece una variante superadora de las estrategias de desarrollo capitalistas hegemónicas, consistentes en el consumo de recursos, y que logró posicionarse a través de un cambio de paradigma resultante, a su vez, de un proceso de resistencia descripto, durante varios los años, por los movimientos sociales. En esta línea, arguye Andino (2014, p. 95) que:

El reconocimiento de la pertinencia del paradigma del Sumak Kawsay para cobijar las aspiraciones de la sociedad ecuatoriana por un proyecto de convivencia que permita cambiar el enfoque de la acumulación material por el de la búsqueda de la armonía entre los seres humanos y con los otros seres vivos y no vivos de la naturaleza, se fue forjando a través de décadas de construcción de discursos y prácticas de protesta en contra de la globalización hegemónica, el modelo de desarrollo extractivista y la inequidad y depredación en la distribución y uso de la tierra y el agua.

Entiende, además, Andino (2014, p. 93) que la ruptura con el viejo paradigma que el modelo del buen vivir propicia se articula sobre tres elementos: i) antes que enfocarse en los individuos se concentre en los intereses colectivos de las comunidades indígenas y afroecuatorianas; ii) desplaza al discurso antropocéntrico al concebir a la persona física como un ser integrante de la naturaleza; iii) modifica el contenido del objeto de la acción social el cual, en lugar de basarse en la acumulación de riqueza, se orienta hacia la búsqueda de la armonía en la convivencia de los seres humanos entre sí y en su interacción con la naturaleza y el entorno.

El concepto del "buen vivir" aparece contemplado en la constitución ecuatoriana de 2008 con diferentes alcances. Así, es asumido como principio, consagrado y desplegado como derecho y también caracterizado como régimen específico (Llasag Fernández, 2009, p. 119). 
De esta manera, en el preámbulo se alude a la decisión de construir "una nueva forma de convivencia ciudadana, en diversidad y armonía con la naturaleza, para alcanzar el buen vivir, el sumak kawsay" (Constitución Ecuatoriana, 2008). A su vez, en el Título II de denominado "Derechos" se destina el Capítulo II a los "Derechos del "Buen Vivir", enunciándose como tales al derecho al "Agua y Alimentación” (Sección Primera, arts. 12 y 13); a un "Ambiente Sano" (Sección Segunda, arts. 14 y 15); a la "Comunicación e Información” (Sección Tercera, arts. 16, 17, 18, 19, 20); a la "Cultura y Ciencia" (Sección Cuarta, arts. 21, 22, 23, 24, 25); a la "Educación” (Sección Quinta, arts. 26, 27, 28, 29); al "Hábitat y Vivienda" (Sección Sexta, arts. 30, 31); a la "Salud" (Sección Séptima; art. 32); y los referentes a la "Trabajo y Seguridad Social” (Sección Octava, arts. 33, 34). Además, tal cual se anticipo, el sumak kawsay es también normado como régimen a través del Título VII, denominado precisamente "Régimen del Buen Vivir", abarcando dos capítulos específicos, cada uno con sus correspondientes secciones2; dedicados el primero de tales apartados a la "Inclusión y Equidad" y el segundo a la "Biodiversidad y los Recursos Naturales".

El recorrido efectuado a través del reconocimiento constitucional que, en las cartas políticas de Bolivia y Ecuador, ostentan los principios éticos de la filosofía indígena andina y la composición plurinacional y multicultural de las respectivas poblaciones de ambos países, permite advertir que las reflexiones sobre el sentido y la relevancia que presenta la economía social y solidaria en tales constituciones debe efectuarse considerando precisamente las implicancias derivadas de la cobertura de aquellos aspectos.

En efecto, esto es así ya que en las citadas leyes fundamentales la inserción de tales cuestiones revela un ensamble funcional dentro del esquema institucional emergente de la letra constitucional que alcanza al modelo de crecimiento y al proyecto de ordenación social consagrado en tales textos. En este sentido lo comprende Coraggio quien, al examinar el

\footnotetext{
2 Constitución de la Republica del Ecuador 2008. Título VII Régimen del Buen Vivir: Capítulo Primero: Inclusión y Equidad (Sección Primera: Educación; Sección Segunda: Salud; Sección Tercera: Seguridad Social; Sección Cuarta: Hábitat y Vivienda; Sección Quinta: Cultura; Sección sexta: Cultura Física y Tiempo Libre; Sección Séptima: Comunicación Social; Sección Octava: Ciencia, Tecnología, Innovación y Saberes Ancestrales; Sección Novena: Gestión del Riesgo; Sección Décima: Población y Movilidad Humana; Sección Undécima: Seguridad Humana; Sección Duodécima: Transporte); Capítulo Segundo: Biodiversidad y Recursos Naturales (Sección Primera: Naturaleza y Ambiente; Sección Segunda: Biodiversidad; Sección Tercera: Patrimonio Natural y Ecosistemas; Sección Cuarta: Recursos Naturales; Sección Quinta: Suelo; Sección Sexta: Agua; Sección Séptima: Biósfera, Ecología Urbana y Energías Alternativas).
} 
tópico en el contexto normativo de la constitución ecuatoriana, considera que el "buen vivir" también adquiere significancia a la hora apreciar el sistema económico consagrado en dicha carta.

En su parecer, la ley fundamental formula una definición sustantiva de economía consistente en sistema de instituciones, valores, normas y prácticas en torno al cual se despliegan los procesos de producción, distribución, circulación y consumo a partir de un complejo de vínculos de cooperación de los trabajos humanos entre sí y con respecto a la naturaleza, que adquiere como sentido la reproducción y desarrollo de la vida expresado en i) la generación de las condiciones materiales necesarias para el sustento y ii) la reproducción intergeneracional ampliada de la vida (Coraggio, 2012).

Es, precisamente, en este punto, en donde el concepto de "buen vivir" evidencia su funcionalidad, ya que, en su criterio, el Sumak Kawsay constituye la forma en la cual se viabiliza esa reproducción ampliada de la vida en la ley fundamental de Ecuador (Coraggio, 2012). Esto implica que el proceso económico debe orientarse hacia la consecución de un equilibrio singularizado en cuatro ámbitos: i) el equilibrio de los seres humanos consigo mismo; ii) El equilibrio entre los seres humanos; iii) El equilibrio de los seres humanos con la naturaleza y iv) El equilibrio entre las comunidades de seres humanos (Coraggio, 2012).

\section{LA ECONOMÍA SOCIAL Y SOLIDARIA EN LAS CONSTITUCIONES DE BOLIVIA Y ECUADOR}

\subsection{LA ECONOMÍA SOCIAL EN EL MARCO DEL MODELO PLURAL BOLIVIANO}

Luego de lo expuesto corresponde examinar la inserción de la economía social y solidaria en las constituciones de Bolivia y de Ecuador, destacándose, en cada caso, su articulación con los respectivos modelos de desarrollo previstos en las cartas políticas de tales países y que se hallan inspirados, tal cual se explicó, por criterios procedentes de la composición plurinacional que caracteriza a sus sociedades. 
El texto constitucional boliviano en su versión de 2009 incluye a la economía social y solidaria dentro del orden económico de naturaleza plural que establece. Tal caracterización deriva, fundamentalmente, de lo previsto en el 306, el cual preceptúa que:

El modelo económico boliviano es plural y está orientado a mejorar la calidad de vida y el vivir bien de todas las bolivianas y los bolivianos. II. La economía plural está constituida por las formas de organización económica comunitaria, estatal, privada y social cooperativa. III. La economía plural articula las diferentes formas de organización económica sobre los principios de complementariedad, reciprocidad, solidaridad, redistribución, igualdad, seguridad jurídica, sustentabilidad, equilibrio, justicia y transparencia. La economía social y comunitaria complementará el interés individual con el vivir bien colectivo (art. 306).

Guardando sintonía con ello, el artículo 311 de la Constitución, además de garantizar que "todas las formas de organización económica establecidas en esta Constitución gozarán de igualdad jurídica ante la ley", concibe a la tipología social y solidaria como una de las vías de realización de la economía plural, al disponer en su inciso 6 to que "el Estado fomentará y promocionará el área comunitaria de la economía como alternativa solidaria en el área rural y urbana".

De esta manera, la economía social y solidaria adquiere un marcado carácter comunitario en la norma constitucional. Justamente, resaltando el origen histórico que caracteriza a este sistema económico que la constitución boliviana de 2009 procura rescatar y atendiendo a la relevancia que dentro del mismo le corresponde a la variante comunitaria, Prada Alcoreza (2010, p. 188) señala que:

De los cuatro ejes de la economía plural, el comunitario goza de especial atención debido a su larga historia y al papel que le toca jugar en el condicionamiento y dirección de los comportamientos y conductas de la mayoría de la población. La comunidad sigue siendo el referente más fuerte de los trueques, las ferias, el trabajo colectivo, el ayni, la minka, la complementariedad subyacente entre los distintos pisos ecológicos, la reciprocidad entre las comunidades.

\subsection{LA ECONOMÍA SOLIDARIA EN EL RÉGIMEN DE DESARROLLO ECUATORIANO}

La constitución ecuatoriana de 2008 instaura un régimen de desarrollo orientado hacia la concreción de un crecimiento equilibrado, de conformidad con el principio del "buen vivir". Puede afirmarse que los propósitos y objetivos que inspiran e impulsan tal diseño económico resultan compatibles con los fines que caracterizan a la economía social y 
solidaria. Ello pude advertirse al examinar el artículo 275 de la Constitución, el cual preceptúa que:

El régimen de desarrollo es el conjunto organizado, sostenible y dinámico de los sistemas económicos, políticos, socio-culturales y ambientales, que garantizan la realización del buen vivir, del sumak kawsay. El Estado planificará el desarrollo del país para garantizar el ejercicio de los derechos, la consecución de los objetivos del régimen de desarrollo y los principios consagrados en la Constitución. La planificación propiciará la equidad social y territorial, promoverá la concertación, y será participativa, descentralizada, desconcentrada y transparente. El buen vivir requerirá que las personas, comunidades, pueblos y nacionalidades gocen efectivamente de sus derechos, y ejerzan responsabilidades en el marco de la interculturalidad, del respeto a sus diversidades, y de la convivencia armónica con la naturaleza (art. 275).

Atendiendo al componente social que la revisión constitucional de 2008 incorpora al desenvolvimiento económico, Pérez Rualez considera que el denominado "régimen de desarrollo", fue concebido por los constituyentes con un alcance amplio, de modo tal que sus dimensiones trasciendan las fronteras impuestas por criterios meramente económicos. En su parecer, este tipo de "Régimen" supone:

Una temática innovadora que engloba no solo el crecimiento económico basado en indicadores macroeconómicos, sino un desarrollo integral que incluye aspectos económicos, sociales, culturales y ambientales, basado en el buen vivir o sumak kawsay, es decir, un modelo en el que las personas y las comunidades gocen de derechos, ejerzan responsabilidades y mantengan una armonía con la naturaleza (Pérez Ruales, 2008, p. 207).

A su vez, el artículo 283, encuadra, de modo expreso, a la economía social y solidaria dentro de la arquitectura económica y financiera prevista en la constitución, al establecer que:

El sistema económico es social y solidario; reconoce al ser humano como sujeto y fin; propende a una relación dinámica y equilibrada entre sociedad, Estado y mercado, en armonía con la naturaleza; y tiene por objetivo garantizar la producción y reproducción de las condiciones materiales e inmateriales que posibiliten el buen vivir. El sistema económico se integrará por las formas de organización económica pública, privada, mixta, popular y solidaria, y las demás que la Constitución determine. La economía popular y solidaria se regulará de acuerdo con la ley e incluirá a los sectores cooperativistas, asociativos y comunitarios (art. 238).

Interpreta Pérez Ruales que este modelo de desarrollo se acentúa sobre una serie de ejes rectores del crecimiento que se apartan del esquema económico implementado por el precedente texto constitucional de 1998. De esta manera, en su opinión, la alternativa social y solidaria comporta un:

Innovador concepto que busca contraponerse y poner límite al 'Sistema de Economía Social de Mercado' que se ha implementado en el país, en el cual, el único objetivo era el crecimiento económico que ha traído consigo una 
insostenible y exacerbada explotación de recursos naturales y un incremento de las inequidades sociales y económicas. Frente a lo cual, el Régimen de Desarrollo de la Constitución se plantea la importancia de la responsabilidad social y ambiental como un eje transversal en todas las temáticas (Pérez Ruales, 2008, p. 207).

\section{REFLEXIONES FINALES}

En Sudamérica la normación constitucional de la economía social y solidaria refleja un panorama caracterizado por diferentes niveles de desarrollo. Ciertamente, ya que la incorporación de previsiones que contemplen específicamente esta modalidad popular de la economía representa aún una consiga pendiente en algunos de los ordenamientos de la región. A su vez, el tratamiento conferido a las actividades e iniciativas de la economía popular en los sistemas jurídicos de los países sudamericanos, así como también la diversa trascendencia que esta modalidad del despliegue económico presenta en las sociedades de los mismos, permite anticipar que el avance en la cobertura constitucional de la cuestión reproducirá, también, las particularidades que ella observa en cada escenario.

Precisamente, la incursión por el encuadre constitucional que recibe la economía social y solidaria en las leyes fundamentales de Bolivia y Ecuador permite apreciar la incidencia de los rasgos específicos que singularizan la expresión del tópico en cada contexto social. Como pudo apreciarse, las constituciones de ambos Estados reconocen a la economía social y solidaria con un sentido similar y le confieren una relevancia, también semejante, como mecanismo de incorporación de determinados segmentos sociales al proceso de desenvolvimiento económico. Sin embargo, también pudo apreciarse que los diferentes matices que median entre las poblaciones de estos países, que resultan recogidos en sus cartas políticas, se reflejan, en alguna medida, en el abordaje constitucional de la economía popular.

Asimismo, tal cual pudo exponerse, las referencias constitucionales de la economía social y solidaria en los dos países citados se encuadran en modelos de desarrollo que, en parte, consideran y se inspiran en la composición plurinacional de sus sociedades y en principios ético-morales de origen indígena revestidos de una sensible connotación para las 
poblaciones respectivas por su conexión con valores arraigados en su acervo histórico. Teniendo en cuenta ello, puede afirmarse que los fundamentos de la economía social y solidaria no sólo resultan compatibles con las pautas contenidas en aquellos conceptos provenientes de cosmovisiones ancestrales; sino que también disponen de virtualidad suficiente para potenciar los fines perseguidos por los modelos de crecimiento, establecidos en los textos constitucionales de ambos Estados a partir de la consideración de aquellas premisas axiológicas históricos.

\section{REFERENCIAS}

ANDINO, Verónica. Continuidades y rupturas entre los enfoques de economía solidaria y desarrollo local. In: JUBETO, Y., GURIDI, L. y FERNÁNDEZ-VILLA, M. (Eds.). Diálogos sobre Economía Social y Solidaria en Ecuador. Encuentros y desencuentros con las propuestas para otra economía. Bilbao: Universidad del País Vasco /Instituto Hegoa, 2014, p. 59-148.

CORAGGIO, José Luis. La economía popular solidaria en el Ecuador. Revista Cooperativismo y desarrollo, Bogotá, $N^{\circ}$ 100, p. 272-280. 2012.

LLASAG FERNÁNDEZ, Raúl. El sumak kawsay y sus restricciones constitucionales. FORO Revista de Derecho, Quito, N 12, p. 113-125. 2009.

PAZ y MIÑO CEPEDA, Juan J. y PAZMIÑO, Diego. El proceso constituyente desde una perspectiva histórica. In: AAVV. Análisis nueva constitución. Quito: ILDIS / La Tendencia Friedrich-Ebert-Stiftung, 2008, p. 26-45.

PÉREZ RUALES, Nicole. Hacia un nuevo modelo de desarrollo. In: ÁVILA SANTAMARÍA, R. (Ed.). La Constitución del 2008 en el contexto andino. Análisis desde la doctrina y el derecho comparado. Quito: Ministerio de Justicia y Derechos Humanos, 2008, p. 201-223.

PRADA ALCOREZA, Raúl. Análisis de la nueva Constitución Política del Estado. In: CHIVI VARGAS, I. M. (Coord.). Bolivia. Nueva constitución política del Estado. Conceptos elementales para su desarrollo normativo. La Paz: Vicepresidencia del Estado Plurinacional, 2010, p. 181-193.

SILVA PORTERO, Carolina. ¿Qué es el buen vivir en la Constitución? In: ÁVILA SANTAMARÍA, R. (Ed.). La Constitución del 2008 en el contexto andino. Análisis desde la doctrina y el derecho comparado. Quito: Ministerio de Justicia y Derechos Humanos, 2008, p. 111-154. 2008

SIMBAÑA, Floresmilo. La plurinacionalidad en la nueva constitución. In: AAVV. Análisis nueva constitución. Quito: ILDIS / La Tendencia - Friedrich-Ebert-Stiftung, 2008, p. 102-117. 
VEGA UGALDE, Silvia. Igualdad y diversidad en la formulación de los derechos. In: AAVV. Análisis nueva constitución. Quito: ILDIS / La Tendencia - Friedrich-Ebert-Stiftung, 2008, p. 86-101.

VEGA, Fernando. El Buen Vivir-Sumak Kawsay en la Constitución y en el PNBV 2013-2017 del Ecuador. OBETS. Revista de Ciencias Sociales, Alicante, Vol. 9, № 1, p. 167-194. 2014. ZAFFARONI, Raúl E. La naturaleza como persona: Pachamama y Gaia. In: CHIVI VARGAS, I. M. (Coord.). Bolivia. Nueva constitución política del Estado. Conceptos elementales para su desarrollo normativo. La Paz: Vicepresidencia del Estado Plurinacional, 2010, p. 109-132. 